Research Article

\title{
Deformation Characterisation and Distress Diagnosis of a Metro Shield Tunnel by Adjacent Constructions
}

\author{
Ting-jin Liu $\mathbb{D}^{1,2,3}$ Si-wei Chen, ${ }^{4}$ and Hong-yuan Liu ${ }^{3}$ \\ ${ }^{1}$ State Key Laboratory of Subtropical Building Science, South China University of Technology, Guangzhou 510640, \\ Guangdong, China \\ ${ }^{2}$ South China Institute of Geotechnical Engineering, South China University of Technology, Guangzhou 510640, \\ Guangdong, China \\ ${ }^{3}$ School of Engineering, University of Tasmania, Hobart 7005, Tasmania, Australia \\ ${ }^{4}$ School of Civil Engineering and Transportation, South China University of Technology, Guangzhou 510640, \\ Guangdong, China
}

Correspondence should be addressed to Ting-jin Liu; liu_tingjin@163.com

Received 16 November 2019; Revised 15 April 2020; Accepted 18 June 2020; Published 4 July 2020

Academic Editor: Lei Wang

Copyright (C) 2020 Ting-jin Liu et al. This is an open access article distributed under the Creative Commons Attribution License, which permits unrestricted use, distribution, and reproduction in any medium, provided the original work is properly cited.

\begin{abstract}
This paper presents a case history of the developmental effect of a large-area excavation, 8 high-rise main buildings, a series of annex constructions, and ground overloaded building demolition on the deformation characteristics of an existing shield tunnel within Guangzhou Metro Line No. 1 in close proximity to the development. The shield tunnel lies in a sandy layer of the typical upper-soft and lower-hard strata in Guangzhou district, and the deformation of the tunnel has been monitored since the tunnel was put into operation. The monitoring results reveal that the adjacent construction induces an excessive tunnel settlement with a maximum of $14.4 \mathrm{~mm}$ and an excess tunnel displacement with a maximum of $5.2 \mathrm{~mm}$, which are within the corresponding limitations of the codes for the safe operation of urban rail transit tunnels. While the station expansion project is being conducted beside the tunnels, a series of tunnel distresses, including large-area water seepage, spalling concrete blocks, and segmental cracks, are recorded. Our field monitoring data indicate that the tunnel is subjected to further vertical contraction and horizontal expansion due to the station expansion project, and a maximum tunnel flattening rate of $36.78 \%$ is detected. Furthermore, the tunnel linings are studied numerically and theoretically to obtain the limitations of tunnel deformation and discuss why tunnel distresses of water seepage, concrete spalling, and segmental cracking occur. Finally, on the basis of the analyses and discussions above, counteracting corrective measures, including compensation grouting soil strengthening and bonded steel plates, are adopted as exterior and interior strengthening methods, respectively, to eliminate further tunnel distresses and ensure safe operation. The lessons learned and summarized in this study may help prevent similar tunnel distresses from reoccurring in the future.
\end{abstract}

\section{Introduction}

With the rapid development of urban transit planning and construction in China and around the world, an increasing number of cities have built underground tunnels to address the increased congestion of ground transportation during recent years. In this case, many underground constructions need to be implemented in close proximity to existing tunnels [1-6]. The excavations of these underground constructions will unavoidably cause soil deformation either inside or outside of the excavation pit or even both, which may severely influence the stability of adjacent structures [7-9].

Tunnel distresses, which threaten tunnel operating safety, occur frequently due to changing conditions in the surrounding soil. A series of tunnel distresses, such as excessive settlements, spalling concrete blocks, and various segmental cracks caused by adjacent constructions, have 
been identified by previous studies. For example, Li and Yuan [10] compared the response of an existing doubledecked tunnel on the Luobao Line of the Shenzhen Metro to closely undercrossing twin shield tunnels on the Shekou Line. In their study, tunnel segmental cracks were carefully recorded and analysed according to dense monitoring data. Huang et al. [11] reported a field case in which an operating shield tunnel was disrupted by the unexpected extreme surcharge caused by adjacent constructions. The longitudinal joints between tunnel lining segments were also severely disrupted and presented large openings. Cheng et al. [12] monitored two shield tunnels passing through two excavation pits and observed that the tunnels were subjected to large-area settlement, ballast separation, segmental cracking, and joint leakage. Based on a practical project, Haorong et al. [13] studied the cause and safety of a damaged segmental structure as well as its relative repair technology and concluded that the reinforcement and repair measures were effective.

Accordingly, to mitigate or even eliminate these tunnel distresses, urgent studies on the limitations of tunnel deformation and corresponding mitigation measures are needed, especially for operating metro tunnels. Huang et al. [14] conducted a finite-element parametric study on tunnel behaviour caused by a nearby deep excavation. They found that the stiffness enhancement of retaining structures was an effective remedial measure to prevent further damage to the existing tunnels. Chen et al. [15] conducted field tests to investigate the effect of major factors affecting deep soilmixing installations. They indicated that soil reinforcement within the excavation area was a successful method to prevent large-scale disturbances. Li et al. [16] concluded that the appropriate construction arrangement and excavation sequence were very effective in reducing the construction time and controlling the soil deformation. Zheng et al. [17] assessed and evaluated the performance and effectiveness of different reinforcing schemes in metro tunnels in Tianjin, China, and concluded that interior reinforcements were more effective than exterior reinforcements in reducing tunnel convergence.

Previous engineering experiences and numerical studies have concluded that the deformation and stress of the existing tunnels and surrounding soils can be greatly impacted by adjacent constructions. Proper repair measures are proven to effectively mitigate these impacts. However, most of these studies focused more on the integrity of the tunnels rather than small tunnel components, which are also crucial parts for preventing incidents and settlement problems.

This paper conducts a case study on the dense tunnel distresses caused by a large-area excavation close to an existing metro tunnel. The induced tunnel distresses were first demonstrated and analysed in detail. The performance of connecting bolts, segmental cracking, and the stress of reinforcements and joint openings are then discussed, which are further analysed numerically and theoretically to obtain the limitations of the tunnel deformation to prevent these tunnel distresses. The methods and experiences presented in this paper can be adopted for constructions adjacent to existing metro tunnels with greater applicability.

\section{Large-Scale Construction Adjacent to Existing Metro Tunnels}

2.1. Introduction. Two shield tunnels of Guangzhou Metro Line No. 1 were constructed in 1993 and put into operation in 1997. The Huangsha station is one of the terminal metro stations of Guangzhou Metro Line No. 1. In 2004, right beside the Huangsha station, the Hehuang project started to be constructed, the worksite layout of which is shown in Figure 1. This project consists of the construction of a nursery school and eight high-rise buildings with the construction process lasting for four years. The worksite comprises a large-area excavation of $8.8 \mathrm{~m}$ to $12.0 \mathrm{~m}$ depth. Bored pile foundations are selected for the eight high-rise buildings, while the nursery school is supported using raft foundations. The minimum horizontal distance between the retaining wall of the excavation pit and the tunnel is $5.7 \mathrm{~m}$. The positional relationship between the excavation pit and the tunnels is shown in detail in Figure 2.

The tunnels are buried $7 \mathrm{~m}$ beneath the ground surface and have an outer diameter of $6 \mathrm{~m}$ and an inner diameter of $5.4 \mathrm{~m}$. The tunnel lining segments are made of concrete of strength grade C40 according to Chinese specifications (standard compressive strength greater than $40 \mathrm{MPa}$ ). The thickness and width of the segments are $0.3 \mathrm{~m}$ and $1.2 \mathrm{~m}$, respectively. Bolts of strength grade 4.6 (yield at $240 \mathrm{MPa}$ ) are chosen for both longitudinal and circumferential connections. For both tunnels, each segmental ring comprises six segments, which include one key segment $(K)$, two top segments $(T)$, and three ordinary segments $(O)$. All segmental rings are assembled in a staggered form for higher stiffness, as shown in Figure 3. A full view of the worksite is presented in Figure 4.

As shown in Figure 5, surface soil levelling commenced in September 2004, followed by a series of different construction stages until the main building completion in November 2008 and the completion of all construction in September 2009. For safety considerations, in tunnel monitoring (every $24 \mathrm{~h}$ ) of the tunnel deformation was conducted from January 2004 to August 2008 when most constructions were completed. The monitoring results indicated that, since the start of construction, considerable settlements and horizontal displacements were observed, and the tunnel had a significant translation towards the foundation pit excavation.

2.2. Engineering Geology. Figure 6 shows the geological profiles along the paths of the tunnels. The geology at the worksite generally contains a $5 \mathrm{~m}$ thick alluvial formation of alternating silt, a $10 \mathrm{~m}$ thick sand formation, and a rock formation below, which represent the typical upper-soft and lower-hard composite strata in the Guangzhou region. The engineering geology shows that the strata surrounding the shield tunnel structure beyond the northern end of the Huangsha station contain mainly fine sand and medium coarse sand. The standard penetration testing (SPT) values of these strata are only 5.0 6.5 hits. However, there is a strong weathered argillaceous siltstone stratum of approximately $1 \sim 2 \mathrm{~m}$ beneath the tunnel, the SPT values of which are 36 42.5 hits, much larger than those of the upper strata. 


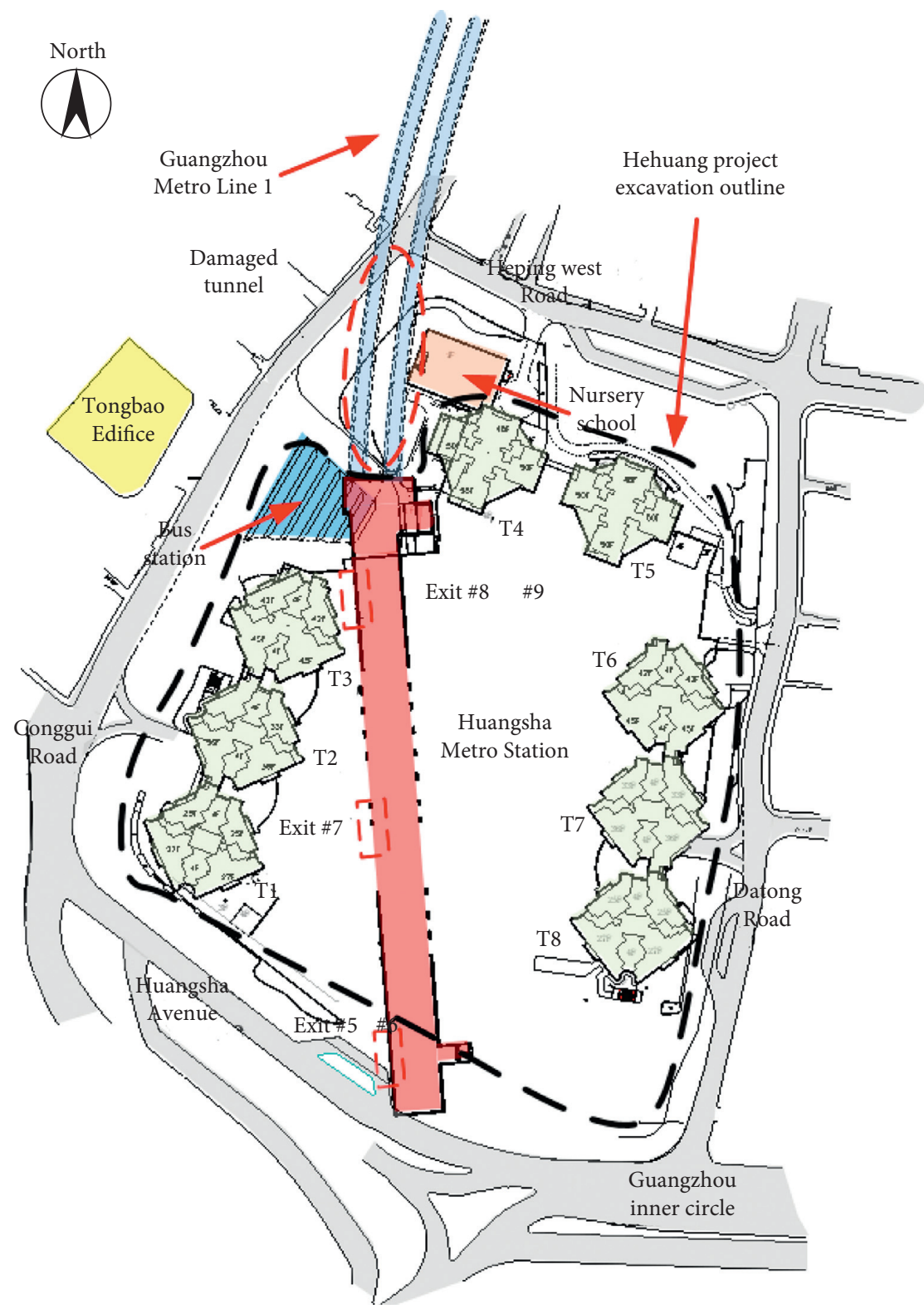

Figure 1: Plan layout of the worksite.

\section{Field Measurements}

Since the completion of the shield tunnel at the northern end of the Huangsha station in 1997, routine tunnel deformation monitoring has been carried out inside the whole metro tunnel. From January 2004, when the Hehuang project commenced, dense monitoring of the tunnel was conducted near the worksite for its operational safety. The monitoring results are detailed in the following sections, which reveal that the deformation of the metro tunnel induced by the Hehuang project from January 10, 2004, to August 16, 2008 (mainly during the process of foundation pit excavation), is close to its corresponding control limitations.

3.1. Tunnel Response before Construction. Figure 7 shows the variation in the tunnel settlement following each measurement. Since November 1999, when the monitoring commenced, until August 2005, that is, before the pit excavation started, the maximum cumulative settlement of the westbound tunnel was measured as $2.25 \mathrm{~mm}$ (at survey station $\mathrm{WK} 5+402$ with a changing rate of $-0.002 \mathrm{~mm} / \mathrm{d}$ ). The maximum cumulative settlement of the eastbound tunnel was $-7.15 \mathrm{~mm}$ (at station EK5 +425.0 with a changing rate of $-0.006 \mathrm{~mm} / \mathrm{d}$ ). The comparison between the variation curves of both tunnels indicated that the settlement of the westbound tunnel fluctuated, while that of the eastbound tunnel showed a mild sinking trend. The absolute settlement magnitude of the eastbound tunnel turned out to be larger, but the settlement tended to be stable. The measured maximum horizontal displacement along the two tunnels was less than $2 \mathrm{~mm}$. Therefore, since completion of the tunnels, only natural small-amount settlements were detected in both tunnels. 


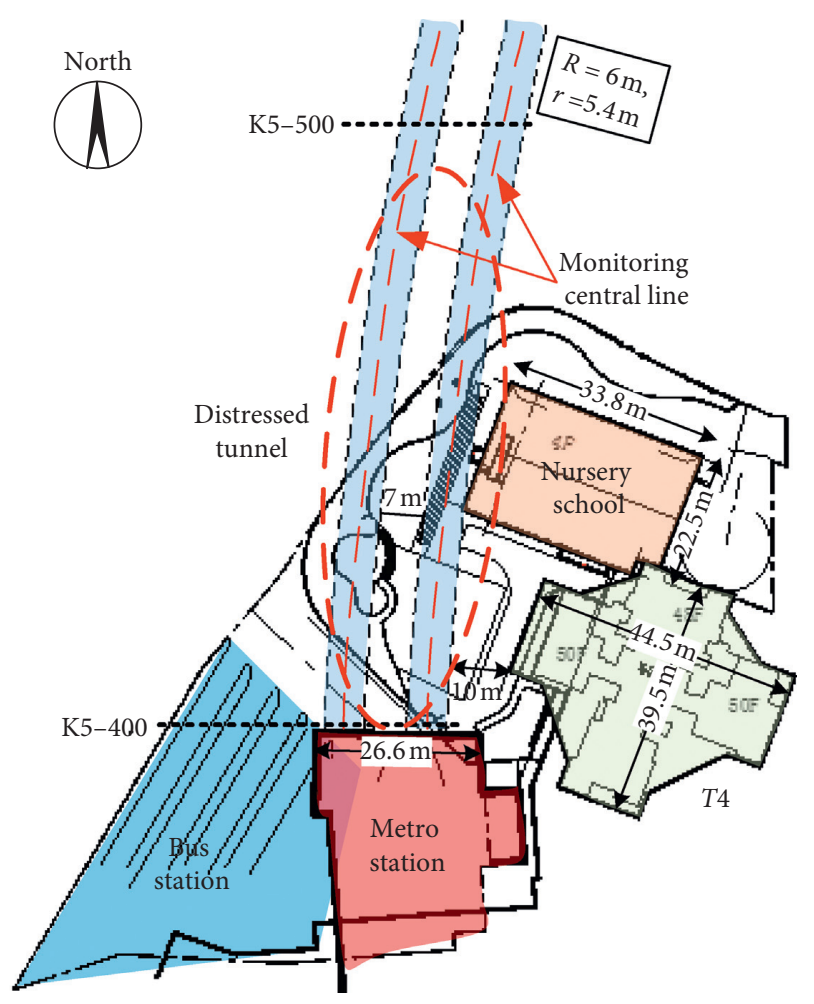

Figure 2: Positions with respect to the tunnel.

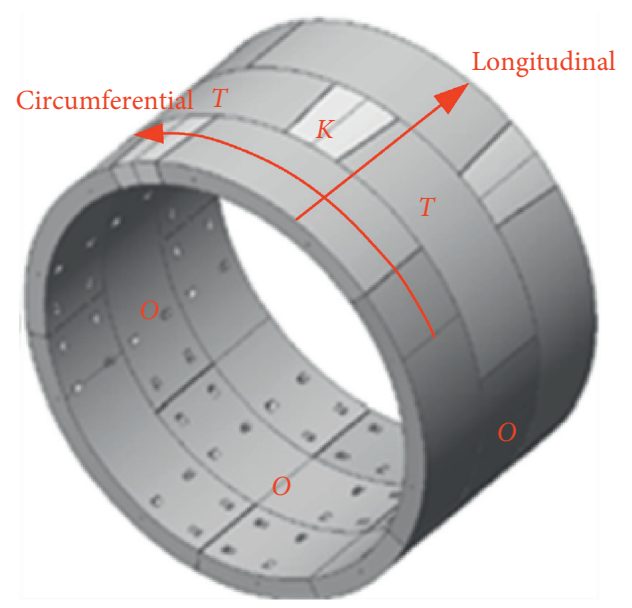

Figure 3: Staggered assembly form.

3.2. Tunnel Response to Construction. Due to the better integrity of the metro station, the impact of the foundation pit construction on the station structure turned out to be relatively small. According to the deformation monitored at the metro station platform on April 2, 2007, the maximum settlement of the metro station was $3.5 \mathrm{~mm}$ vertically.

Figure 8 shows a schematic sketch of the deformation measuring points installed inside the metro tunnel. The measuring rings are $10 \mathrm{~m}$ apart. Figure 9 shows photographs of both the measuring instruments and the prisms. As shown in Figure 8 , the positive direction of the $X$-axis of the monitoring coordinate system points along the tunnel path starting from the station, the positive direction of the $Y$-axis

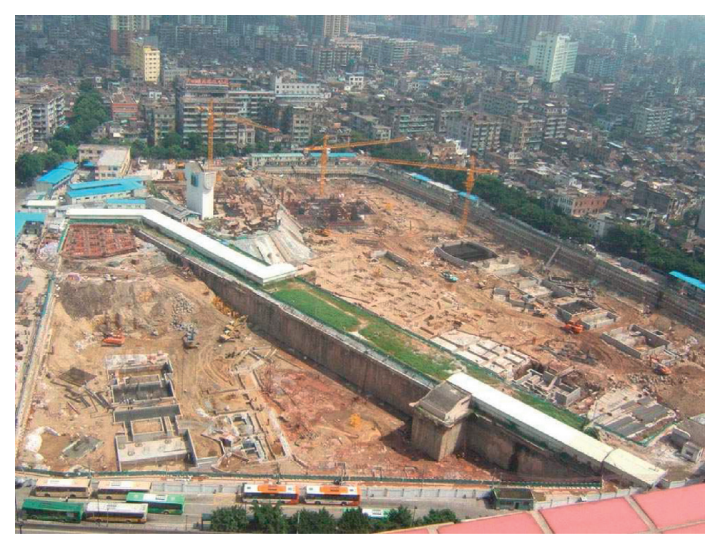

Figure 4: Full view of the worksite.

is directed from the westbound tunnel to the eastbound tunnel (towards the northwest corner of the excavation pit), and the positive direction for the $Z$-axis is directed vertically upward to the ground. Within the monitoring time interval (from Jan. 10, 2004, to Aug. 16, 2008), the average monitored data were taken as the integral tendency for each measuring circle, and the measurements are plotted in Figures 10-13 against the distance starting from the northern end of Huanghua Station $(\mathrm{K} 5+400)$.

Figure 10 shows the integral displacements monitored at each measuring circle of the westbound and eastbound tunnels along the tunnel path starting from Huangsha station. It can be summarized from the variation curves that the deformation of both tunnels occurred mainly in the interval of 0 to $70 \mathrm{~m}$ from the north end of the station, especially in the $Y-Z$ planes (Figure 8 ). The integral translation of the tunnel in this range generally faced the inside of the excavation pit in the northwest corner ( $Y$-positive in Figure 8). Vertical settlements were also observed in both tunnels, while the monitored displacements along the tunnel path were much smaller than those in the $Y-Z$ planes. For the westbound tunnel, the maximum horizontal displacement was measured as $2.6 \mathrm{~mm}$, while the settlement was $-14.4 \mathrm{~mm}$, which was detected $30 \mathrm{~m}$ from the north end of the station. For the eastbound tunnel, the maximum horizontal displacement was measured as $5.2 \mathrm{~mm}$, while the settlement was $-5.1 \mathrm{~mm}$. According to different levels of deformation, the whole tunnel can be divided into three ranges: (a) heavy disturbance $(0$ to $70 \mathrm{~m})$, (b) moderate disturbance (70 to $100 \mathrm{~m}$ ), and (c) mild disturbance (more than $100 \mathrm{~m}$ ). In addition, the section from $10 \mathrm{~m}$ to $60 \mathrm{~m}$ was defined as the alert range.

An interesting fact is noticed from the variations in the monitored tunnel displacements. Although the average horizontal displacement of the eastbound tunnel was apparently larger than that of the westbound tunnel, the average vertical settlements of the westbound tunnel turned out to be even larger than those of the eastbound tunnel within the alert range defined above, despite the eastbound tunnel being closer to the excavation foundation pit. The authors attributed this difference to the mitigation effect of the demolition of the police station, which was just above the 

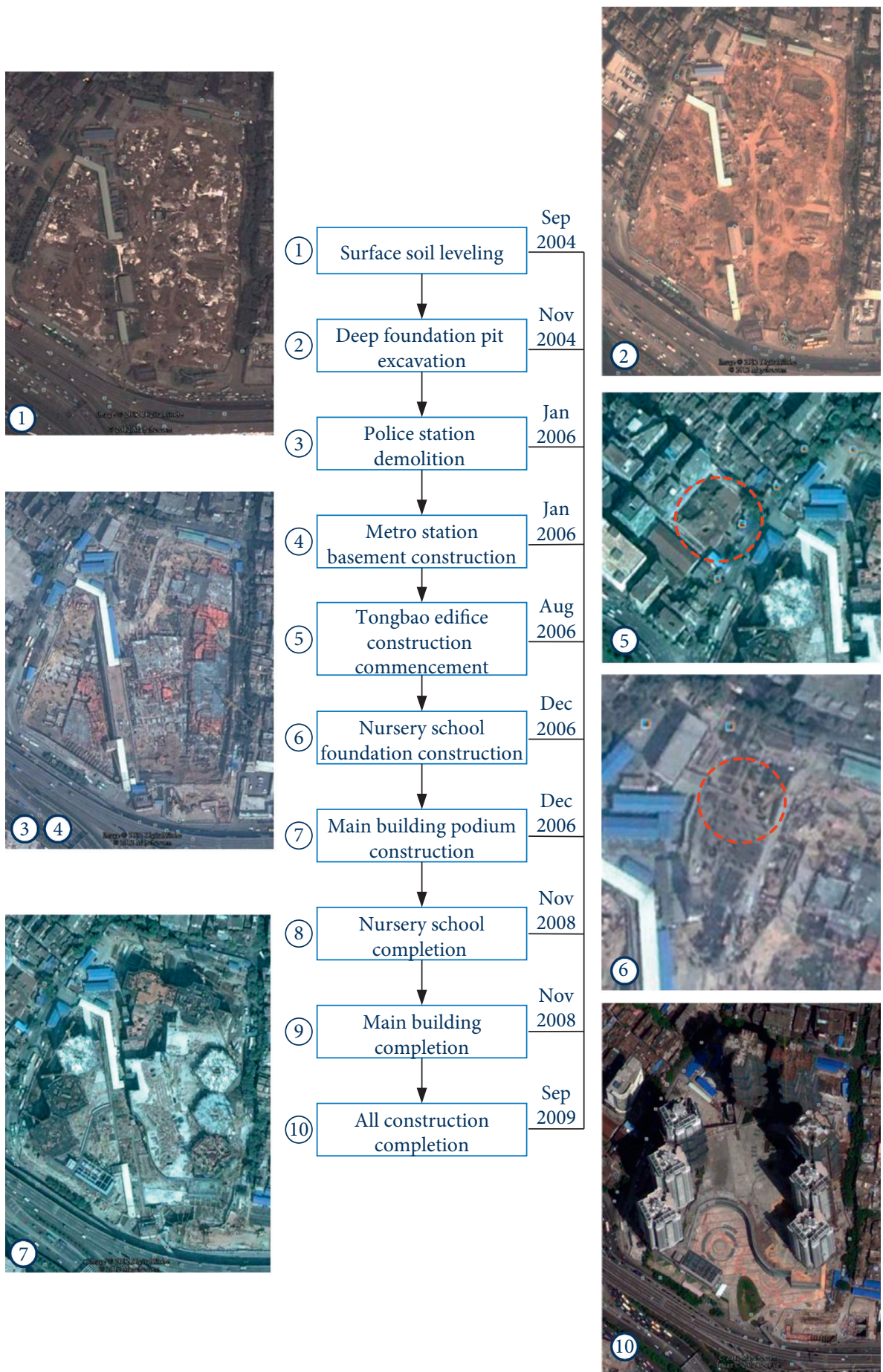

FIgURE 5: Flowchart showing the major stages of construction.

eastbound tunnel before demolition and right in the position where the nursing school lay, as shown in Figures 1 and 2.

Figure 11 plots the variation in the absolute displacements monitored on the track beds, which are often adopted as a tunnel distress stage assessment criterion in practical engineering. The limitation of the absolute displacement of $4 \mathrm{~mm}$ on the track bed was recommended to ensure tunnel safety. It can be concluded from Figure 11 that the largest displacements were detected within the range from 0 to
$60 \mathrm{~m}$, which is consistent with the tendency observed above. Moreover, the settlements governed the fluctuating amplitude for all three directions, and the maximum settlement was $3.2 \mathrm{~mm}$ monitored on the track bed at $30 \mathrm{~m}$ from the north end of the station in the westbound tunnel.

Figure 12 shows the curvature radius, equal to the radius of the circular arc, which best approximates the curve at that point of the vertical and horizontal directions of the westbound and eastbound tunnels caused by the pit excavation. 


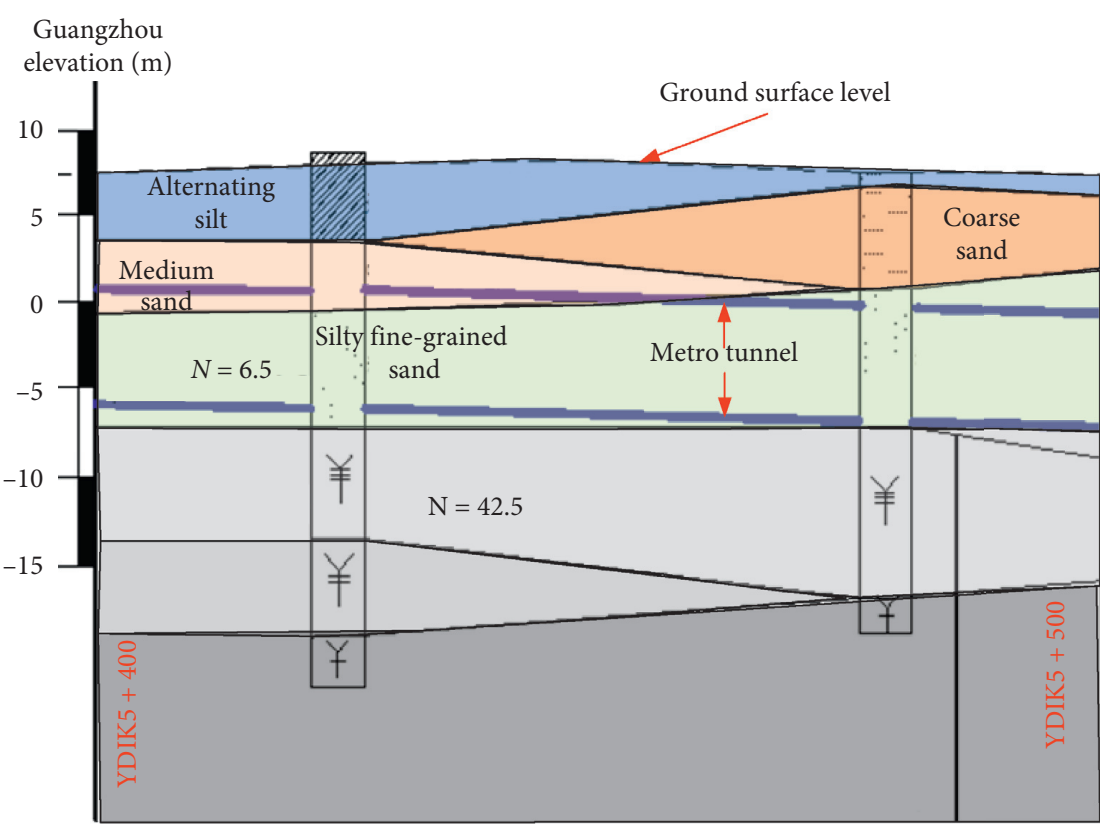

(a)

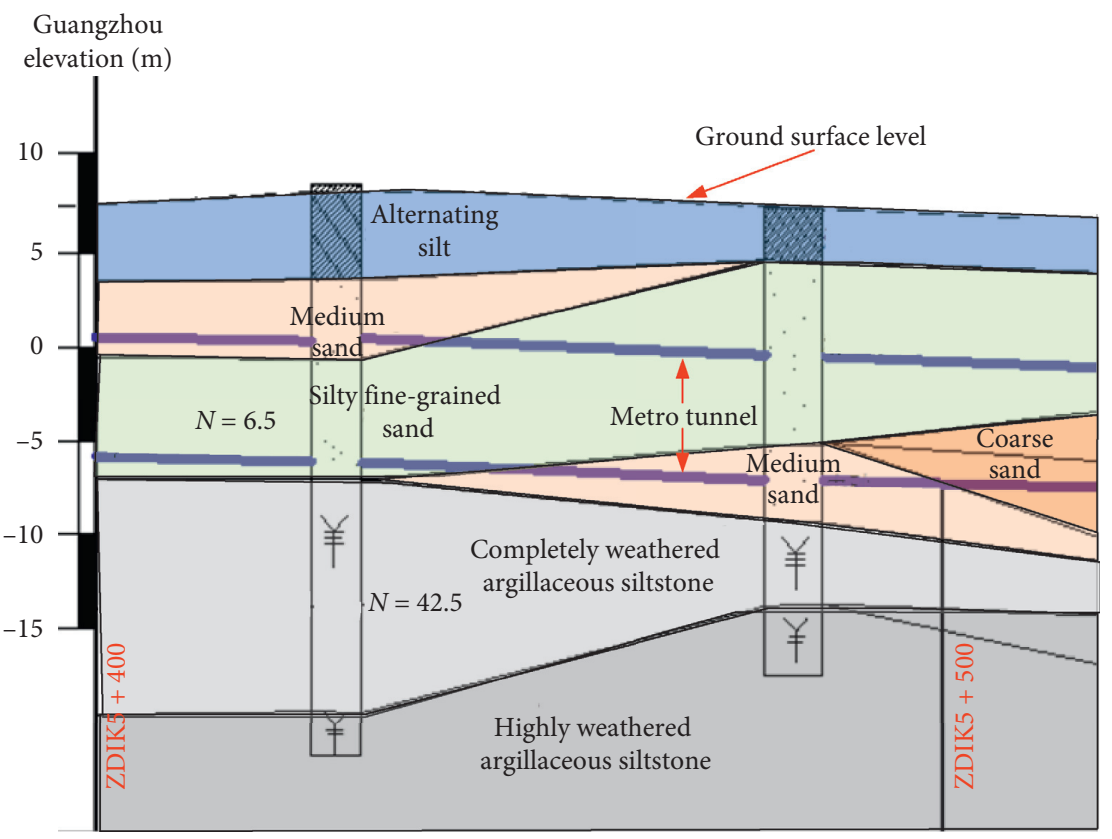

(b)

FIGURE 6: Geological profiles of the tunnels. (a) Geological profile of the eastbound tunnel. (b) Geological profile of the westbound tunnel.

The smaller curvature radius of both tunnels was mainly concentrated in the $0-80 \mathrm{~m}$ section of the tunnels. The minimum radius of curvature in the horizontal plane was $19,500 \mathrm{~m}$, occurring $60 \mathrm{~m}$ from the north end of the station, while that in the vertical plane was $17,167 \mathrm{~m}$, occurring $30 \mathrm{~m}$ away from the north end of the station. This outcome is also consistent with what was observed in Figure 10.

Figure 13 shows the variation in the tunnel convergence due to pit excavation. The convergence of the eastbound tunnel between measuring points No. 3 and No. 5 reached a peak with a maximum of $9.1 \mathrm{~mm}$, which occurred $20 \mathrm{~m}$ from the station north end, while the maximum convergence of the westbound tunnel between measuring points No. 2 and No. 5 was $16.0 \mathrm{~mm}$, which occurred $40 \mathrm{~m}$ away from the north end of the station. Again, the main convergence occurred mainly in the heavy disturbance range as described above. Moreover, a larger amount of tunnel convergence was observed in the westbound tunnel than in the eastbound tunnel, while the eastbound tunnel was closer to the pit excavation. It is believed that the horizontal translation of the eastbound tunnel drove 


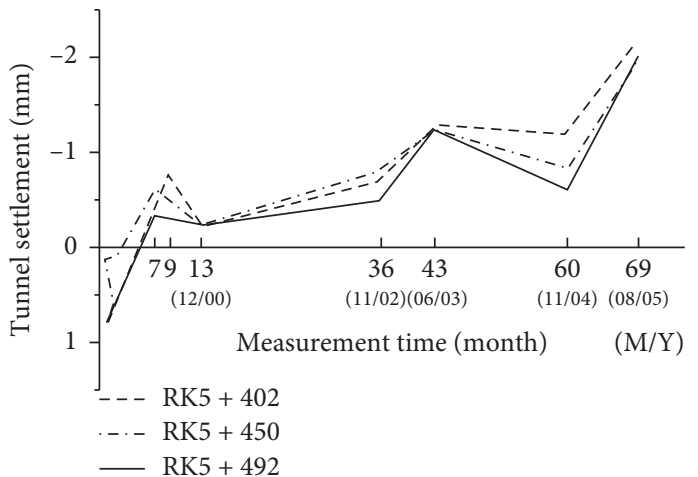

(a)

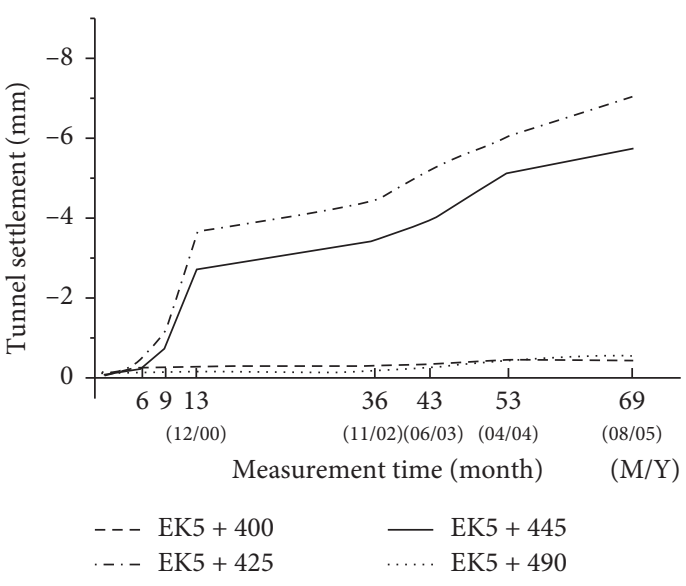

(b)

FIGURE 7: Variations in tunnel settlement before construction: (a) westbound tunnel and (b) eastbound tunnel.

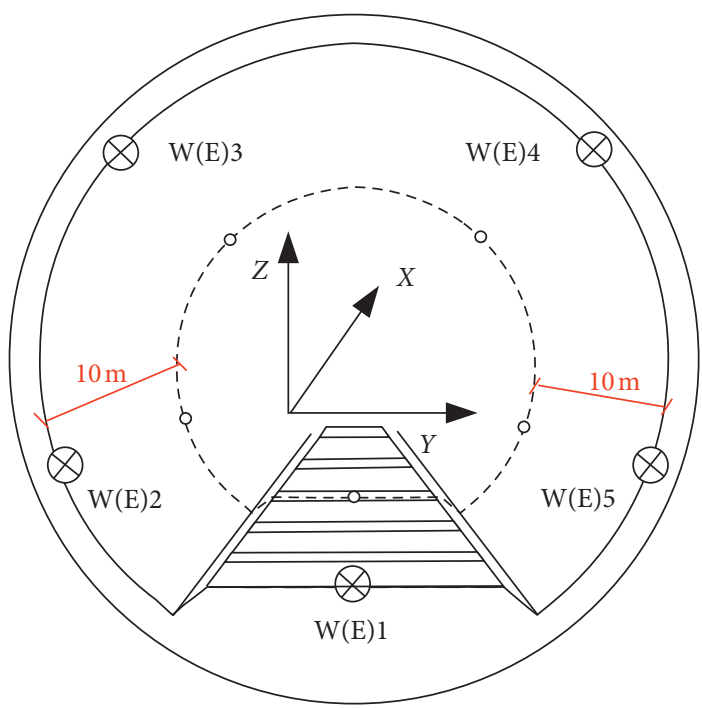

FIGURE 8: Schematic for measuring arrangements.

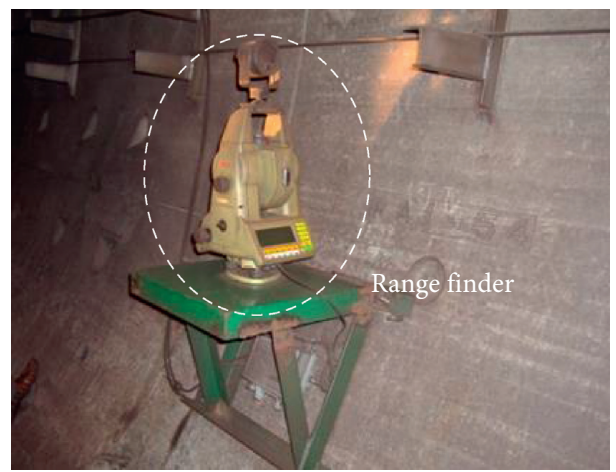

(a)

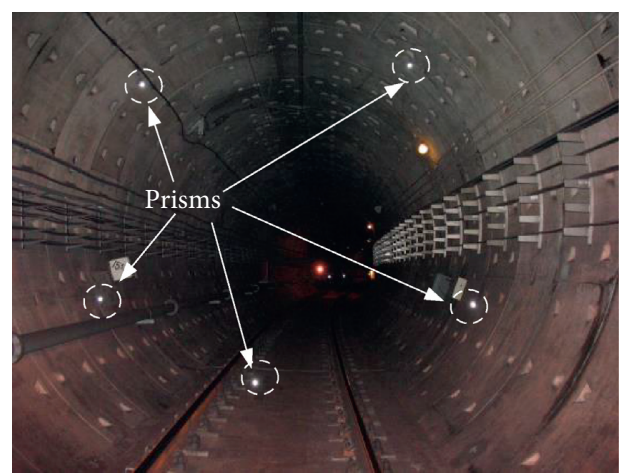

(b)

FIgUre 9: Photo in the actual tunnel: (a) laser range finder and (b) prisms.

the soil between the tunnels to have a follow-up movement, which weakened the lateral support of the soil above the westbound tunnel. Due to the weakened lateral support, the soil above the westbound tunnel pressed even harder on the westbound tunnel structure, resulting in larger vertical contractions and horizontal expansions, as monitored above. 


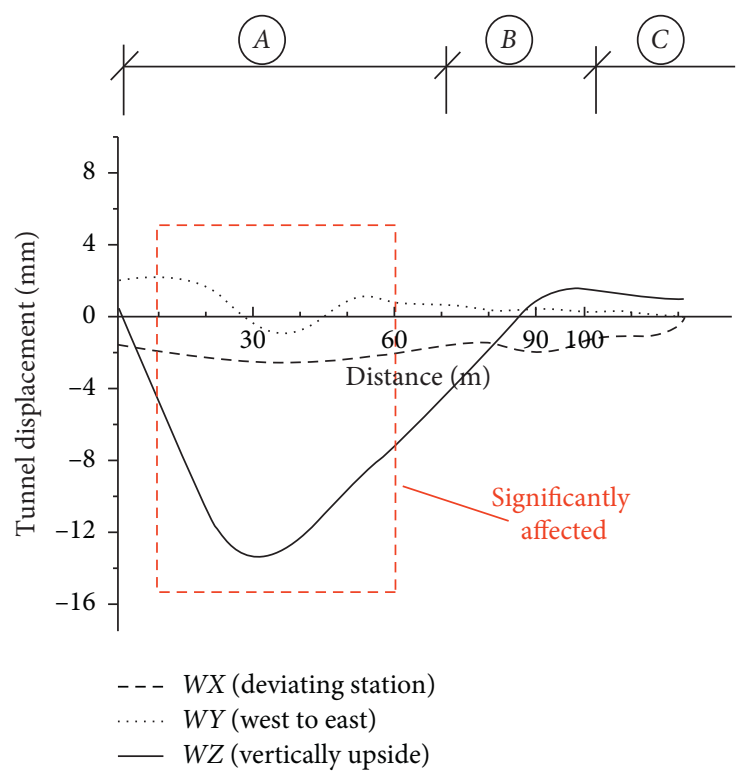

(a)

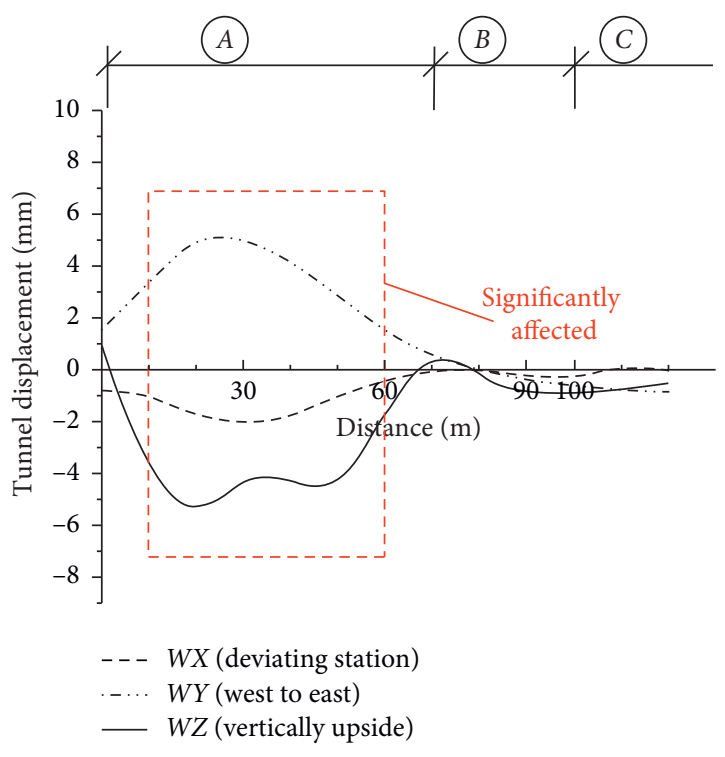

(b)

FIGURE 10: Variations in tunnel displacement: (a) westbound tunnel and (b) eastbound tunnel.

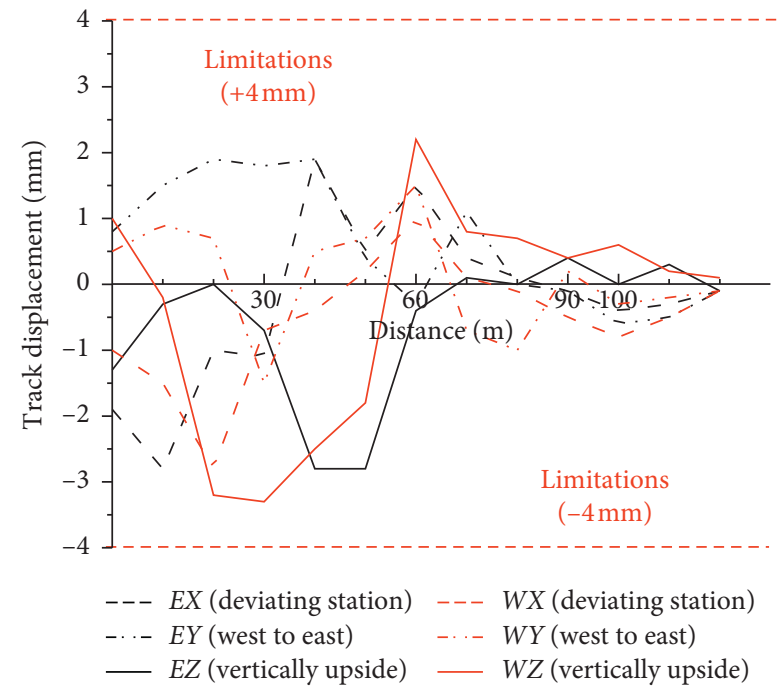

Figure 11: Variations in track bed displacement.

Table 1 summarizes the maximum values of the variables of the metro tunnels monitored during the construction process and their comparisons with the corresponding limitations regulated in the Chinese code [18] for the safe operation of urban rail transit tunnels. From the comparisons, the current monitored data showed that the deformations of the metro tunnel induced by the construction of the Hehuang project from January 10, 2004, to August 16, 2008 (mainly during the construction process of the foundation pit), approached the corresponding limitations, although the tunnel was still in a safe state.

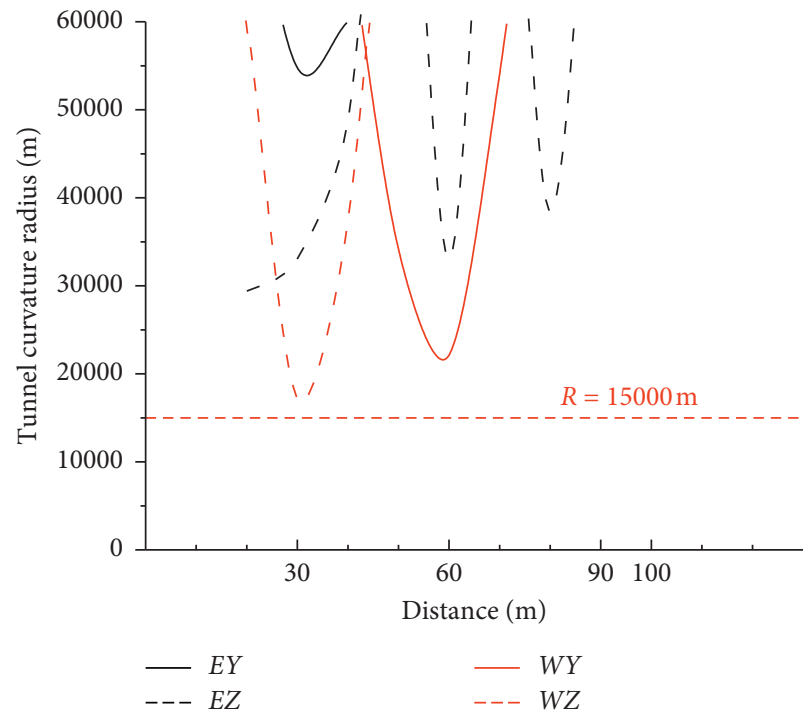

FIGURE 12: Variations in tunnel curvature radius.

\section{Tunnel Distress Diagnosis}

At the end of 2010, the metro operating department decided to carry out the Huangsha station expansion project, and five new gates marked as \#5 to \#9 in Figure 1 would be built for the station. Two months later, upon finishing the project, water seepage through the gates was observed over a large area, as shown by the photos in Figure 14. At midnight on Jan 9, 2011, mass concrete blocks were found on the track bed of the westbound tunnel $4 \mathrm{~m}$ away from the north end of Huangsha station during routine metro tunnel inspection. 


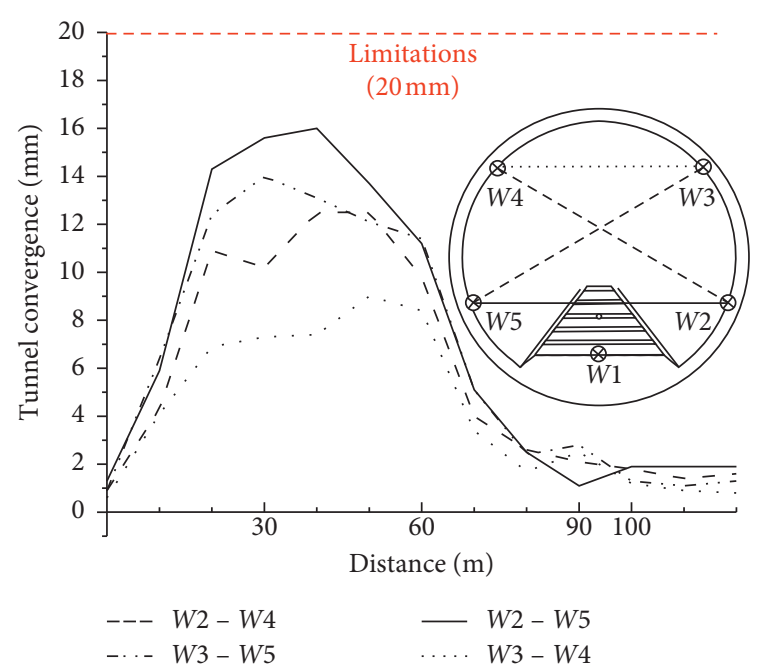

(a)

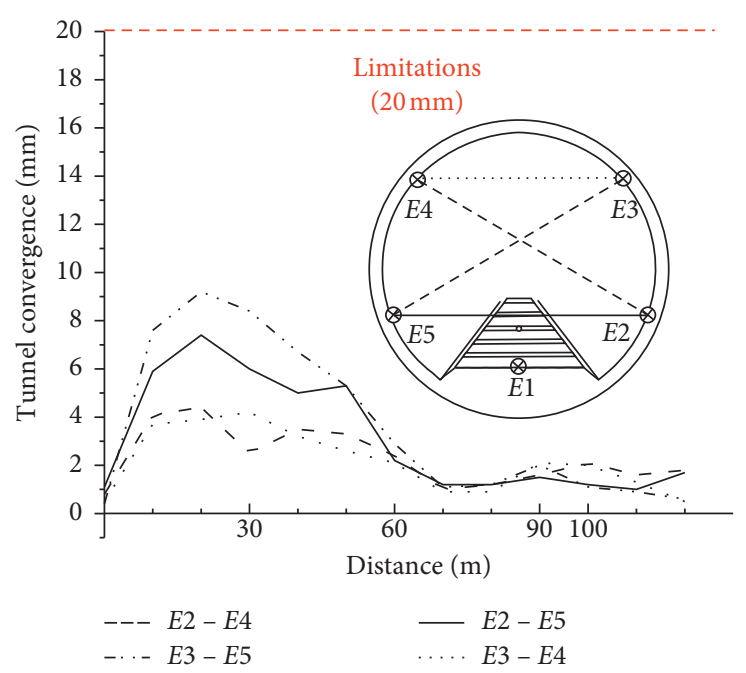

(b)

Figure 13: Variations in tunnel convergence: (a) westbound tunnel and (b) eastbound tunnel.

TABLE 1: Monitoring peak value against limitations.

\begin{tabular}{|c|c|c|c|}
\hline \multicolumn{2}{|c|}{ Monitoring type } & Peak value & Limitations \\
\hline \multirow{2}{*}{ Displacements } & Settlements $(\mathrm{mm})$ & -14.4 & \pm 20 \\
\hline & Translation $(\mathrm{mm})$ & -5.2 & \pm 20 \\
\hline \multicolumn{2}{|c|}{ Convergence $(\mathrm{mm})$} & 16.0 & 20 \\
\hline \multicolumn{2}{|c|}{ Track displacements $(\mathrm{mm})$} & 3.2 & 5 \\
\hline \multicolumn{2}{|c|}{$Y$ curvature radius $(\mathrm{m})$} & 19,500 & 15,000 \\
\hline \multicolumn{2}{|c|}{$Z$ curvature radius $(\mathrm{m})$} & 17,167 & 15,000 \\
\hline
\end{tabular}

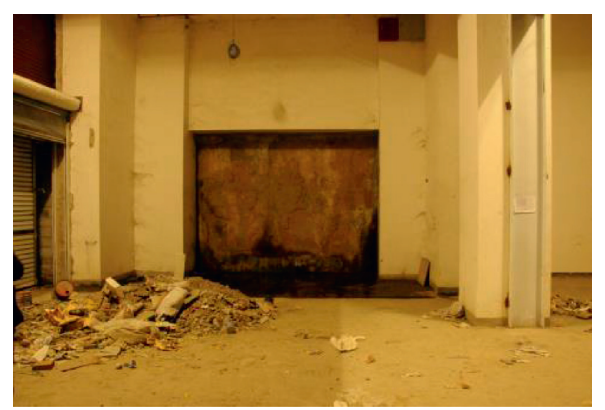

(a)

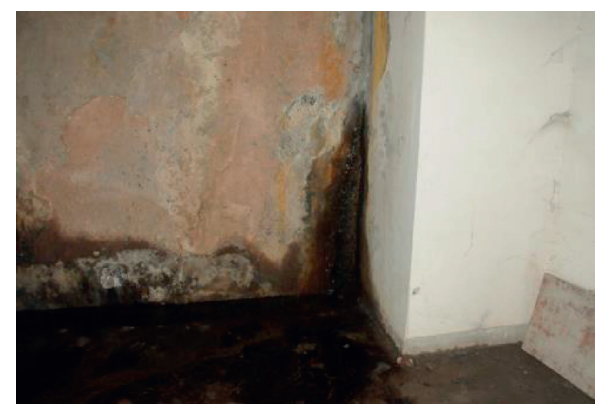

(b)

FIGURE 14: Water seeping inside the station.

Those blocks were confirmed to be from a top cracked longitudinal segmental joint $(\mathrm{K} 5+404.8)$. For safe metro operation, professional investigations were conducted to determine the current safety status of the tunnel and how to prevent further tunnel deterioration, which are presented in the following sections.

4.1. Spalling Concrete Blocks. In the westbound tunnel, 19 spalling concrete blocks were detected, where segmental reinforcements as well as nine segmental bolts were directly exposed to air. The maximum size of the dropped block was
$57 \times 13 \times 10 \mathrm{~cm}$, located on the $38^{\text {th }}$ ring $(45.6 \mathrm{~m}$ away from the north end of the station). Within the alert range, the broken segments comprised $14.2 \%$ of the total 84 segmental rings. Spalling concrete blocks were mostly found around the circumferential segmental joints in the tunnel vault (known as the key segment). The measured exposure rate of the reinforcements was $14.4 \%$ and that of the bolts was $10.7 \%$ along the complete alert range of the westbound tunnel. In the eastbound tunnel, 11 spalling concrete blocks were found with segmental reinforcements and bolts directly exposed to the air. The largest size of detached concrete was $56 \times 10 \times 10 \mathrm{~cm}$, which was located at the fifth ring $(6 \mathrm{~m}$ away 
from the station). After the investigation, the spalling concrete blocks were removed, and the broken segments were then amended with grouting mortar, which is shown in the photographs taken in situ in Figure 15.

Among the spalling blocks found in both tunnels, 76.7\% were found along circumferential joints (between the segments of the same ring), and $23.3 \%$ were found along longitudinal joints (between the segmental rings). Examples of the spalling blocks around the circumferential and longitudinal joints are shown in the photos in Figure 16, while the amount and location of the falling blocks found in both tunnels are presented in Figure 17. A smaller stiffness between the longitudinal segmental rings was believed to contribute to less stress on the concrete along corresponding hand holes, which is why fewer longitudinal spalling blocks were found.

Therefore, both tunnels had undergone large deformation at that time, which led to partial stress concentration on the segments, and the series of spalling concrete blocks indicated that the tunnel should be in a severe state. As a result, a detailed investigation of segmental cracks was carried out to determine how the tunnel was damaged and to what extent the tunnel should be strengthened, which are presented in the following sections.

4.2. Segmental Cracks. 143 cracks were detected in the westbound tunnel, and 119 cracks were identified in the eastbound tunnel. Most of the cracks propagated throughout the segments along their width (i.e., the length exceeded $1.20 \mathrm{~m}$ ). The maximum widths of the cracks were measured to be $0.53 \mathrm{~mm}$ and $0.51 \mathrm{~mm}$, appearing on the $22 \mathrm{nd}$ segment (26.4 $\mathrm{m}$ away from the station) and 47 th segment $(56.4 \mathrm{~m}$ away from the station) in the westbound and eastbound tunnels, respectively, which are shown in the photographs taken in situ in Figure 18.

According to the analysis presented later in Section 5 , the segments with different crack widths were then classified into three groups according to their maximum crack widths, as shown in Table 2. Figure 19 shows the distribution of the cracking segments with various crack widths, where a red circle indicates a cracking segment with a maximum crack width $w \geq 0.38 \mathrm{~mm}$, a blue triangle indicates a maximum crack width $0.31 \mathrm{~mm} \leq w<0.38 \mathrm{~mm}$, and a black rectangle indicates a maximum crack width $w<0.31 \mathrm{~mm}$. The classifications are discussed later in Section 5. The cracking segments with large crack widths were mostly found within the alert range of the tunnels, which was consistent with the tunnel deformation responses described in Section 3. Apparently, the cracking was more severe in the segments of the westbound tunnel than that in the eastbound tunnel. To determine how the tunnel deformed, postdistress monitoring was then conducted, and the results are shown in Section 4.4 .

4.3. Leakage through Joints. Due to the increase in Earth pressure on the tunnel, the segmental joints were found to be opening to a larger amount. Soil, water, sand, and mud gushed through the openings. A total of 13 intersegment water leaks were identified in the westbound tunnel, which mostly accompanied the large cracks on the segments. In the eastbound tunnel, six intersegment water leaks were also identified. Approximately $25 \mathrm{~m}$ away from the north end of the station, the track bed concrete ditch on the side near the foundation pit of the Hehuang project had cracked with a small area of mud seeping out, which is shown by the photo in Figure 20 taken in the field.

4.4. Tunnel Flattening Rate. The tunnel flattening rate measurement was first implemented in Feb. 2011. Another measurement of the tunnel flattening rate was carried out after emergency countermeasures were taken in Sep. 2011. The flattening rate is defined hereby as the ratio of the difference between the horizontal and vertical diameters to the horizontal diameter. The laser measuring instrument employed in the tunnel flattening rate assessment possessed a distance measuring accuracy of $1 \mathrm{~mm}$ and a flattening rate measuring accuracy of $2 \%$. In the westbound tunnel, the largest flattening rate of $36.78 \%$ was detected on the 12 th segmental ring (14.4 $\mathrm{m}$ away from the north end of the station), while the flattening rates of the $20^{\text {th }}$ to $50^{\text {th }}$ segment rings ( $24 \mathrm{~m}$ to $60 \mathrm{~m}$ away from the north end of the station) of the eastbound tunnel were large, with a maximum flattening rate of $32.62 \%$, which is shown in Figure 21.

The positive value of the flattening rate indicates that both tunnels sustained horizontal expansion and vertical convergence along the tunnel path, which validates the previous results reported in Section 3. Considering the distributions of both spalling blocks and segmental cracks (see Figures 17 and 19, respectively), the high values of the curvature radius and flattening rate (see Figures 12 and 21) always corresponded to concentrations of concrete spalling blocks and larger segmental cracks. Moreover, their excessive values represented larger Earth pressure concentrations sustained by the segmental rings. After the area where the segmental rings were affected the most was identified, steel plates were adhered to the inner surface of the segmental rings to strengthen the tunnel inside, and adjacent backfilling soils were grouted to strengthen the outside of the tunnel. As a result, the flattening rate for both tunnels decreased integrally from Feb. 2011 to Sep. 2011, which could be primarily attributed to the counteractive emergency measures taken.

\section{Analysis and Discussion}

This section will analyse and discuss different deformation stages of the tunnel structures under typical working conditions. To determine the tunnel response to the surrounding soil interaction, numerical simulation was undertaken using a finite-element commercial package, Midas GTS. Theoretical deduction based on Chinese specifications was also conducted to provide limitations on shield tunnel structural deformation. The results obtained from this section provide effective references for rectifying problems. 


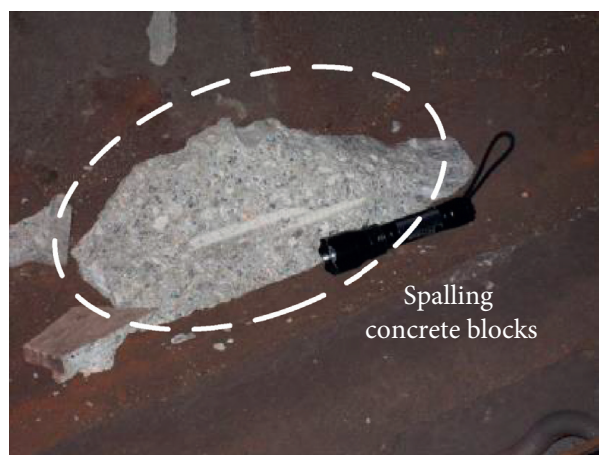

(a)

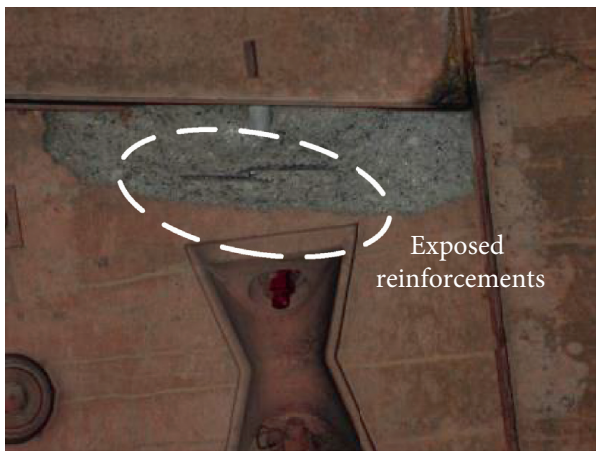

(c)

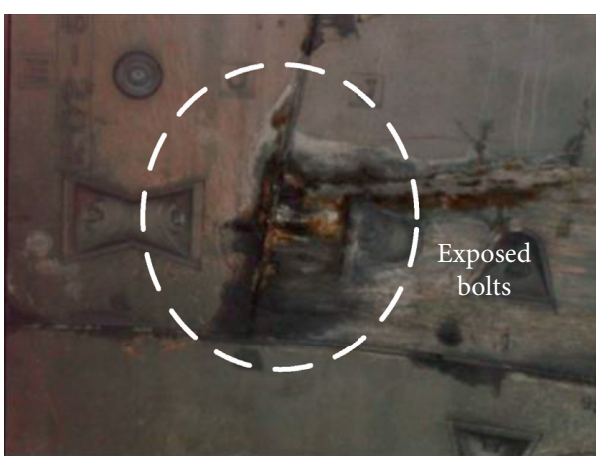

(b)

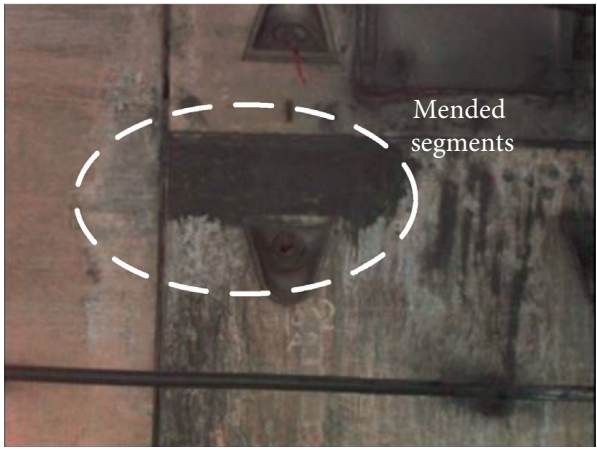

(d)

FIGURE 15: (a) Spalling blocks, (b) exposed bolts, (c) exposed reinforcements, and (d) mended segments.

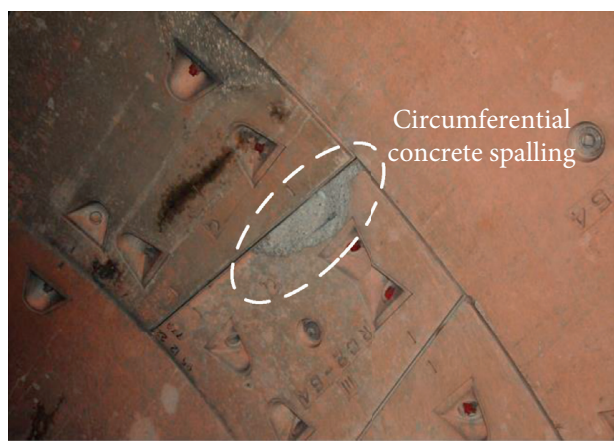

(a)

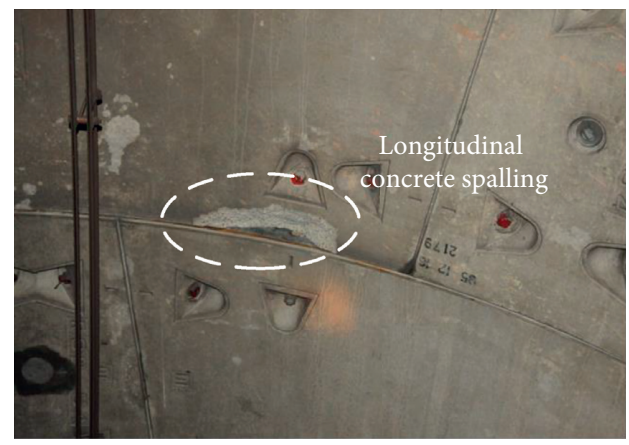

(b)

Figure 16: Two types of concrete spalling.

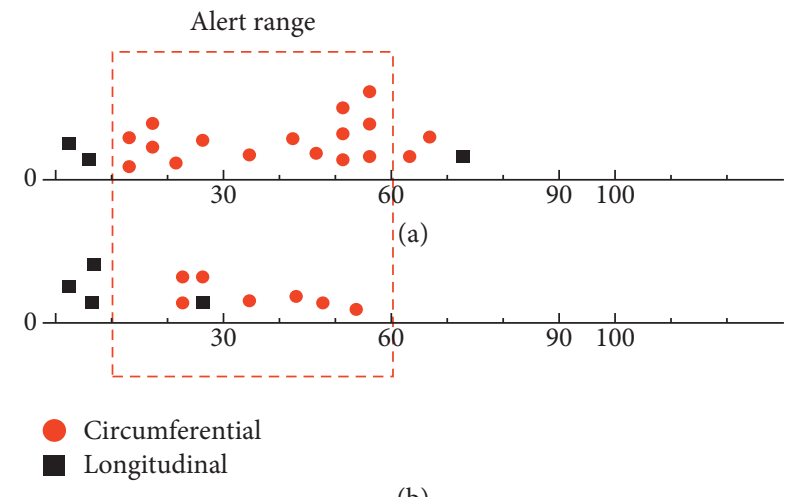

(b)

FIGURE 17: Distribution of spalling blocks: (a) westbound tunnel and (b) eastbound tunnel.
5.1. Numerical Simulation. The reinforced lining structure consists of segments, steel rebars, connecting bolts, and waterproof strips. Thus, three kinds of materials, including concrete, steel, and rubber, should be introduced. In the finite-element analysis presented herein, the total strain crack model is adopted to describe the nonlinear response of concrete under excessive loads. For the steel material, the von Mises model is implemented. The uniaxial tensile/ compressive stress-strain relations of C40 concrete and the yield hardening behaviour of steel are introduced according to the parameters provided by the standards in China [19]. The waterproof strip made from ethylene-propylene-diene monomer (EPDM) rubber is simplified as a linear elastic material because the rubber strip is designed to remain in an elastic state to meet waterproofing requirements. Figure 22 


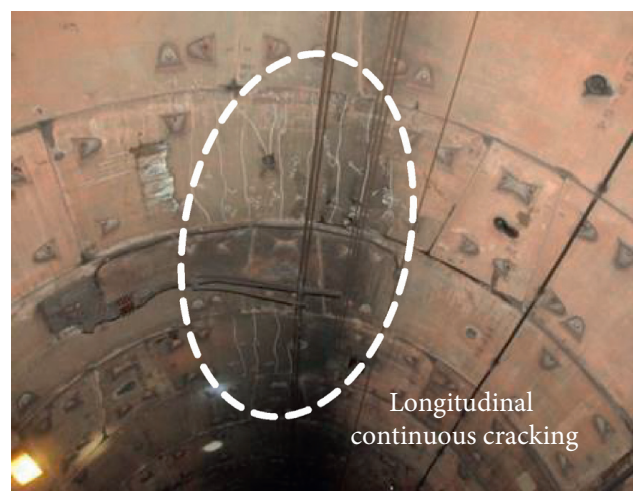

(a)

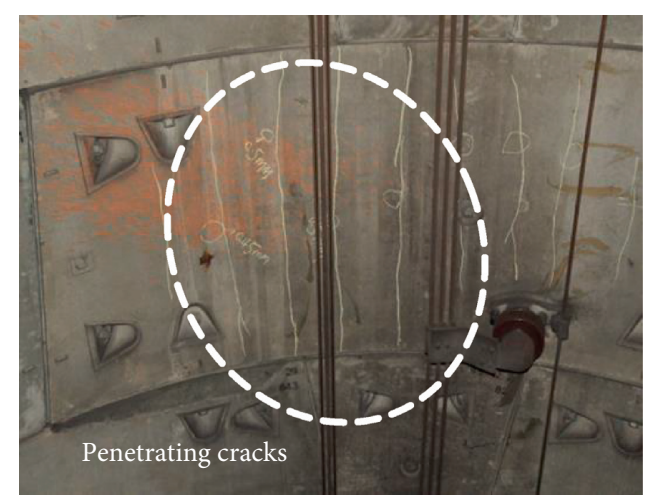

(b)

Figure 18: Cracking tunnel.

TABle 2: Crack summation.

\begin{tabular}{lcc}
\hline Crack width $(\mathrm{mm})$ & Amount & Proportion $(\%)$ \\
\hline$w<0.31$ & 197 & 75.19 \\
$0.31 \leq w<0.38$ & 23 & 8.78 \\
$w \geq 0.38$ & 42 & 16.03 \\
Total & 262 & 100.00 \\
\hline
\end{tabular}

shows the 3D detailed FE model. Typical working conditions were simulated to discuss possible incentives for an excessive tunnel flattening rate. Table 3 summarizes the induced deformation under each working condition.

Computational results clearly show that, under normal working conditions, the deformation of the shield tunnels turns out to be very small. Regardless of the variation in the lateral soil pressure (even inactivity), the yielding of the connecting bolts ( $10 \%$ reduction in the stiffness of the bolts), or the cracking of the segments, the tunnel structure would deform slightly with a small equivalent-severe flattening rate. The equivalent-severe flattening rate would be larger than the actual rate with the same maximum deformation. However, the maximum measured flattening rate (see Figure 21) turned out to be even larger, which indicated that the soil surrounding the tunnel should be loosened. The computational results supported the distress incentives concluded later in Section 5.3. With a reduction in the Earth pressure, the equivalent-severe flattening rate was even smaller than the largest one measured. Therefore, in the alert ranges of both tunnels, a portion of the connecting bolts yielded. The results also showed that the segments would crack if a larger flattening rate was measured, which is also consistent with the results from in situ observations, as shown in Figure 21.

5.2. Theoretical Analysis. Based on the Chinese code "Codes for design of concrete structures [19]" (GB50010-2010), theoretical calculations are conducted to analyse the relationship between the crack width and reinforcement tensile stress and the relationships among the joint opening magnitude, curvature radius, and joint moment for the concrete segmental lining.
5.2.1. Reinforcement Stress Analysis. This paper adopts a quasipermanent combination and considers the formula for calculating the maximum crack width affected by long-term effects, which are shown in the following four equations:

$$
\begin{gathered}
\omega_{\max }=\alpha_{c r} \psi \frac{\sigma_{s}}{E_{S}}\left(1.9 c_{s}+0.08 \frac{d_{e q}}{\rho_{t e}}\right), \\
\psi=1.1-0.65 \frac{f_{t k}}{\rho_{t e} \sigma_{s}}, \\
d_{e q}=\frac{\sum n_{i} d_{i}^{2}}{\sum n_{i} v_{i} d_{i}} \\
\rho_{t e}=\frac{A_{S}+A_{P}}{A_{t e}} .
\end{gathered}
$$

For the bending components of the concrete segmental lining, the tensile stress in the tension zone can be obtained by the following fd5equation:

$$
\sigma_{s q}=\frac{M_{q}}{0.87 h_{0} A_{s}} .
$$

In equations (1)-(5), $\omega_{\max }$ represents the maximum crack width affected by long-term effects, $a_{c r}$ is the stress characteristic coefficient of the eccentric compression members, $\psi$ denotes the strain unevenness coefficient of longitudinal reinforcements between the cracks, $\sigma_{s}$ denotes the equivalent tensile stress, $c_{s}$ is the protective layer thickness, $d_{e q}$ represents the equivalent diameter of the stretched reinforcements, $\rho_{t e}$ denotes the longitudinal stretched reinforcements ratio using the effective stretched concrete area $A_{t e}, A_{P}$ indicates the prestressed reinforcements area, $\sigma_{s q}$ represents the tensile stress of reinforcements under bending moments, and $M_{q}$ is the moment.

The parameters of the concrete segment lining are the segment width $b=1200 \mathrm{~mm}$, thickness $h=300 \mathrm{~mm}$, tensile reinforcement area $A_{s}=1765 \mathrm{~mm}^{2}$, reinforcement elastic modulus $E_{s}=2.00 \times 10^{5} \mathrm{~N} / \mathrm{mm}^{2}$, effective height of the section $h_{o}=257 \mathrm{~mm}$, standard value of concrete strength (strength grade C40) $f_{t k}=2.39 \mathrm{~N} / \mathrm{mm}^{2}$, stress characteristic coefficient of eccentric compression members $a_{c r}=1.9$, effective tensile 


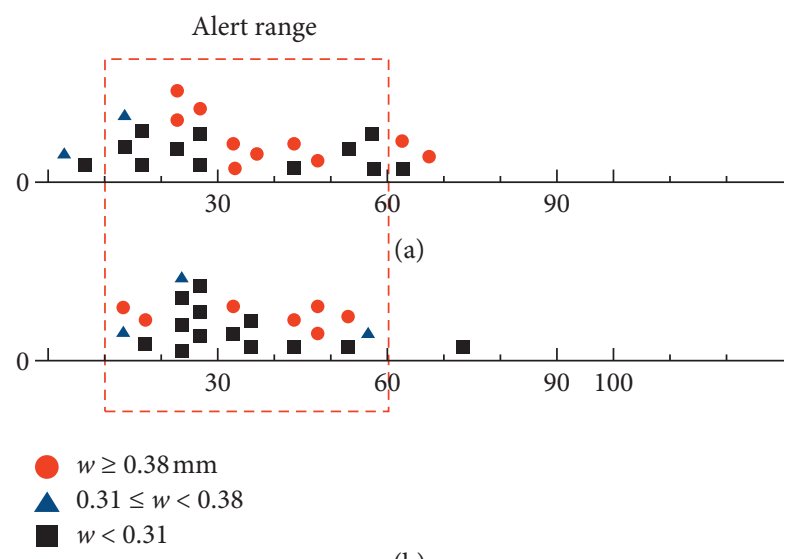

(b)

FIGURE 19: Distribution of cracking segments: (a) westbound tunnel and (b) eastbound tunnel.

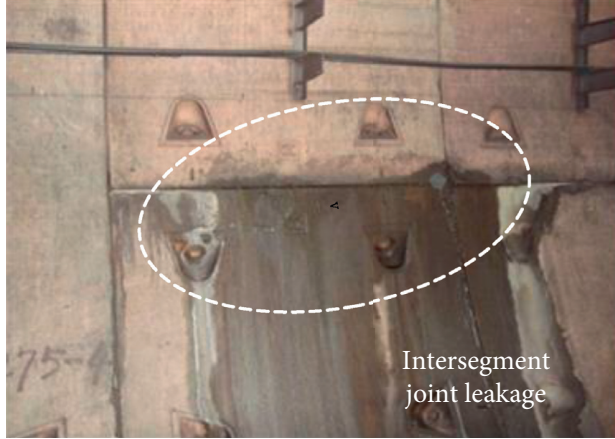

(a)

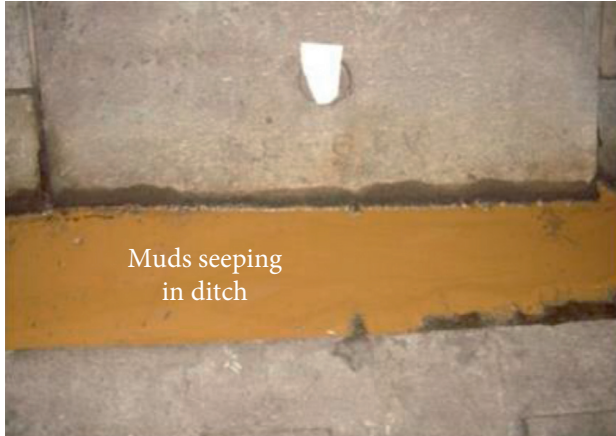

(b)

FIgURE 20: Joint leakage.

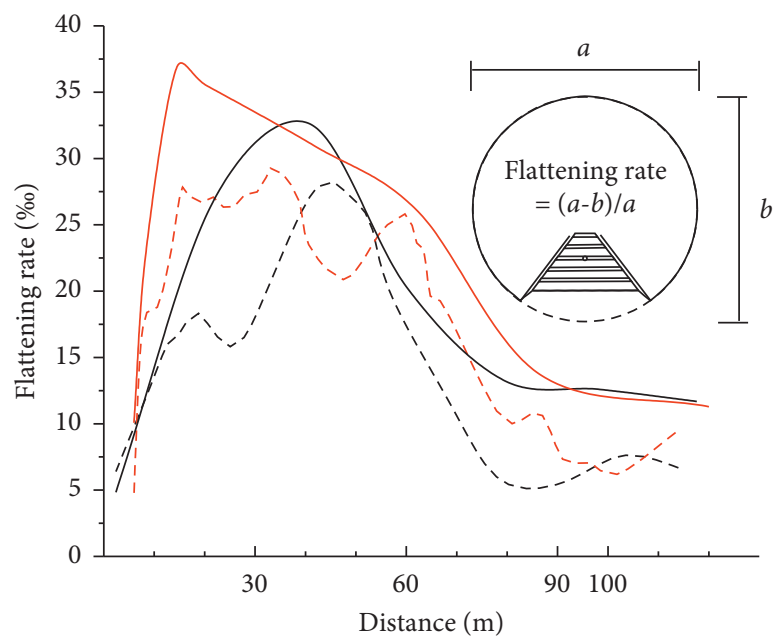

— Eastbound, Feb _ - - - Eastbound, Sep

- Westbound, Feb _ - - - Westbound, Sep

FIgURE 21: Tunnel flattening rate.

concrete cross-sectional area $A_{t e}=180,000 \mathrm{~mm}^{2}$, and reinforcement bar equivalent diameter $d_{e q}=15.19 \mathrm{~mm}$. Moreover, the reinforcements yield at $335 \mathrm{MPa}$.
Using equations (1)-(5) and the parameters listed above, the crack width, the reinforcement bar stress, and the bending moment of the segment can be inversely calculated. 


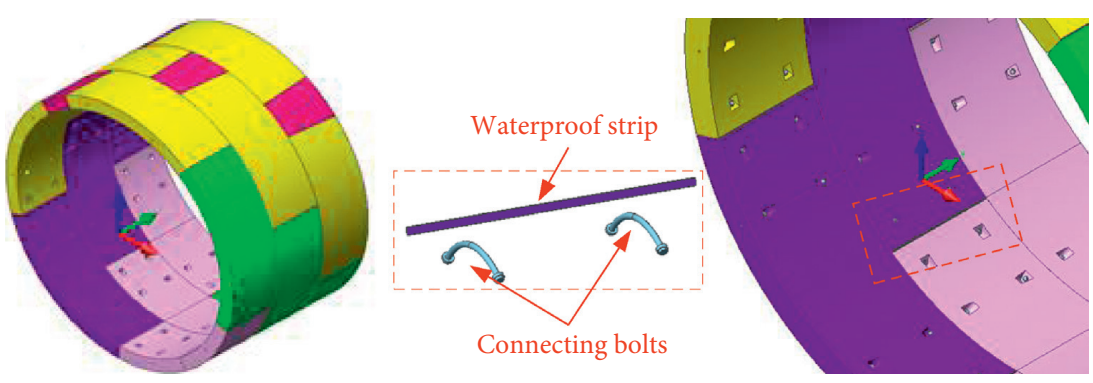

FigURE 22: Staggered assembly of segments.

TABLE 3: Crack summation.

\begin{tabular}{|c|c|c|c|}
\hline & Working conditions & $\begin{array}{l}\text { Maximum } \\
\text { deformation }(\mathrm{mm})\end{array}$ & $\begin{array}{c}\text { Flattening rate } \\
(2 \times \max ) /(d+\max )\end{array}$ \\
\hline \multirow{5}{*}{ Normal earth pressure } & No reduction in bolt stiffness & 2.4 & $0.8 \%$ \\
\hline & No lateral soil pressure, no reduction in bolt stiffness & 6.1 & $2.3 \%$ \\
\hline & $10 \%$ reduction in bolt stiffness & 2.7 & $1.0 \%$ \\
\hline & $\begin{array}{l}\text { No reduction in bolt stiffness, } 100 \mathrm{~mm} \text { cracking depth on } \\
\text { segments }\end{array}$ & 7.1 & $2.7 \%$ \\
\hline & $\begin{array}{l}\text { No reduction in bolt stiffness, } 200 \mathrm{~mm} \text { cracking depth on } \\
\text { segments }\end{array}$ & 8.8 & $3.2 \%$ \\
\hline \multirow{4}{*}{$\begin{array}{l}\text { Earth pressure with } 10 \% \\
\text { reduction }\end{array}$} & No reduction in bolt stiffness & 10 & $3.4 \%$ \\
\hline & $10 \%$ reduction in bolt stiffness & 46 & $16.9 \%$ \\
\hline & $\begin{array}{l}10 \% \text { reduction in bolt stiffness, } 100 \mathrm{~mm} \text { cracking depth on } \\
\text { segments }\end{array}$ & 54 & $19.8 \%$ \\
\hline & $\begin{array}{l}10 \% \text { reduction in bolt stiffness, } 200 \mathrm{~mm} \text { cracking depth on } \\
\text { segments }\end{array}$ & 69 & $25.2 \%$ \\
\hline
\end{tabular}

The results show that when the crack width of the segment reaches $0.38 \mathrm{~mm}$, the reinforcement bar yields, and the corresponding segment moment is $132 \mathrm{kN} \bullet \mathrm{m}$. For segments with a larger crack width, the moment sustained by the segments will be even greater. Table 4 summarizes the relationships among the crack width, stress of the reinforcement bar, and moments of the segments.

5.2.2. Joint-Opening Analysis. To obtain the relationships between the bolt stresses and joint moments, the same parameters are taken except that the effective height of the section is changed to $180 \mathrm{~mm}$. The connecting bolts between the segment linings yield at $240 \mathrm{MPa}$. The opening amount of the rigid segment joint can be approximated by equation (6), where $R$ is the curvature radius of the adjacent segment ring according to the measured data of the longitudinal deformation of the tunnel, $D$ is the thickness of the segment, and $L$ is the length of the segment ring.

$$
S=\frac{L \times D}{R} \text {. }
$$

Figure 23 plots the calculation diagram for equation (6) and Table 5 summarizes the relationships among the curvature radius, joint opening, bolt stress, and joint moment.

When the longitudinal deformation curvature radius of the shield tunnel exceeds $15,000 \mathrm{~m}$, both the opening amount and the bolt stress are considerably at a low level. If the curvature radius is smaller than $14,429 \mathrm{~m}$, the bolts would yield, and the longitudinal bending stiffness of the tunnel would decrease rapidly. When the curvature radius of the tunnel decreases by $1,200 \mathrm{~m}$, the opening amount of the segmental joint reaches $6.00 \mathrm{~mm}$ or more, the waterproof strip in the joint may fail under the design water pressure, and the tunnel is subjected to water seepage and leakage.

5.3. Distress Incentives. Combined with the geological surveying report and engineering monitoring data, the main reasons for the water seeping into the station and the tunnel distresses can be concluded as follows:

(1) Upon the completion of the foundation pit, the excavations need to be backfilled with soils. Unfortunately, after backfilling, the soils were not compacted densely enough, resulting in a greater porosity than that of the compacted soil. Moreover, considering the atmospheric precipitation and replenishment of surrounding surface water, an upper aquifer layer with a large water content was then formed. The aquifer layer generated high hydrostatic pressures around the Huangsha station and tunnels. As soon as a weak gap was encountered, water leakage occurred.

(2) When the operating department was opening the gates, no waterproof countermeasures were 
TABLE 4: Relationships among crack width, stress of the reinforcements, and moments of the segments.

\begin{tabular}{lccccccccc}
\hline Crack width $(\mathrm{mm})$ & 0.1 & 0.2 & 0.3 & 0.31 & 0.38 & 0.4 & 0.5 & 0.6 & 0.62 \\
\hline Reinforcement stress $(\mathrm{MPa})$ & 192 & 243 & 294 & $\mathbf{3 0 0}$ & $\mathbf{3 3 5}$ & 345 & 396 & 447 & 455 \\
Moments $(\mathrm{kN} \bullet \mathrm{m})$ & 76 & 96 & 116 & $\mathbf{1 1 8}$ & $\mathbf{1 3 2}$ & 136 & 156 & 176 & 180 \\
\hline
\end{tabular}

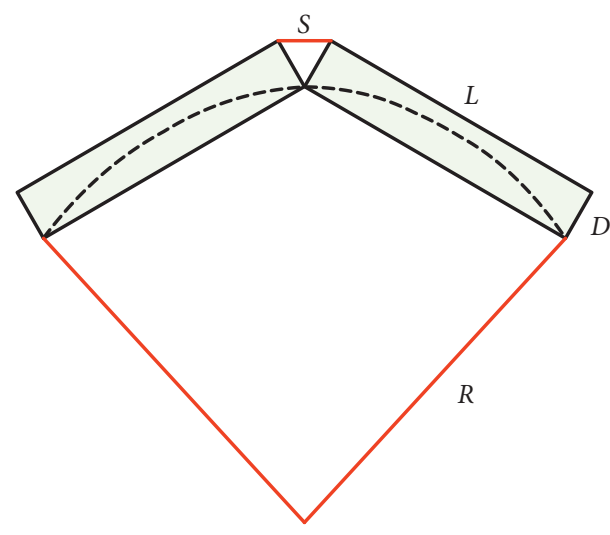

FIGURE 23: Calculation diagram.

TABLE 5: Relationships among the curvature radius, joint opening, bolt stress, and joint moment.

\begin{tabular}{lccccccc}
\hline $\begin{array}{l}\text { Curvature } \\
\text { radius }(\mathrm{m})\end{array}$ & 19000 & 15000 & 14429 & 3600 & 1800 & 1200 & 176 \\
\hline $\begin{array}{l}\text { Joint opening } \\
(\mathrm{mm})\end{array}$ & 0.33 & 0.48 & $\mathbf{0 . 5}$ & 2 & 4 & $\mathbf{6}$ & 38.56 \\
$\begin{array}{l}\text { Bolt stresses } \\
(\mathrm{MPa})\end{array}$ & 170 & 208 & $\mathbf{2 4 0}$ & 247 & 255 & $\mathbf{2 6 3}$ & 400 \\
$\begin{array}{l}\text { Joint } \\
\text { moments } \\
(\mathrm{kN} \bullet \mathrm{m})\end{array}$ & 21.29 & 26.32 & $\mathbf{2 9 . 8 7}$ & 30.82 & 31.79 & $\mathbf{3 2 . 7 7}$ & 49.41 \\
\hline
\end{tabular}

conducted. Due to the gap between the continuous wall of the project and the retaining structure of the Huangsha Metro station, the previously compressed water continuously leaked through the opened station gates and intersegment joints into the openings.

(3) Since the leaking rate of the water out of the aquifer layer was faster than the replenishing rate, the volume of groundwater decreased, and the groundwater level decreased, which resulted in an increase in the effective pressure on the extrados of the tunnel. On the other hand, the groundwater flow could easily result in sand losses in the stratum surrounding the tunnel structure. As a result, the stratum surrounding the tunnel became even looser, reducing the constraining force on the tunnel and causing larger tunnel deformation.

During the project construction period, management errors and omissions were also deemed to be some of the causes of the excessive deformation and the distress on the tunnels. These errors and omissions can be summarized as follows:

(1) Guangzhou Metro Line No. 1 was the first shield tunnel metro line built in southern mainland China.
There were indeed quite a few flaws in the tunnel structural design. As an example, the design was not suitable for the complicated strata in the Guangzhou region. At that time, the design regulations of shield tunnels in China were not thoroughly considered, and the construction management group also lacked relevant experience. All these defects led to inherent deficiencies in the metro tunnel.

(2) Excavation backfilling was not conducted immediately. Too much time was taken for excavating the Hehuang project foundation, which greatly impacted the tunnel stability. Moreover, due to the close proximity to the tunnels, the construction of the retaining structure was not allowed to cause a large disturbance, resulting in a weak deformation resistance of the retaining structures.

(3) On the commencement of the station expansion project, in situ tunnel monitoring was not conducted as required. Large-area tunnel distresses were first identified by routine metro tunnel inspection rather than in situ tunnel monitoring. However, for safety considerations, the alerts of tunnel distresses should first be made by in situ tunnel monitoring because the abnormal flattening rate apparently occurred earlier than the spalling concrete blocks or segmental cracks.

Due to the large-area water seepage into the Huangsha station, the gradation of the surrounding soil had changed, and the effective pressure on the tunnel had increased. Since the tunnel deformation induced by the excavation had already approached its limitations, a series of tunnel distresses occurred as a result. Further deterioration of the tunnel safety was then induced. The authors would like to share with all researchers and engineers the lessons learned from the flawed construction management to prevent the repetition of similar mistakes.

\section{Counteracting Measures}

Since tunnel distresses such as falling concrete blocks, dozens of cracks on segments, joint leakage, and excessive tunnel flattening rates outlined above were observed in February 2011, counteractive measures were taken to mitigate these tunnel distresses.

The compensation grouting soil-strengthening method was undertaken for exterior strengthening. The soil inside the retaining wall of the excavation pit was strengthened by double-row $\Phi 700$ mm @500 mm double-tube rotary jetting piles. The foundation pit backfilling soils were grouted and reinforced to at least a depth of $13 \mathrm{~m}$ (exceeding the bottom 


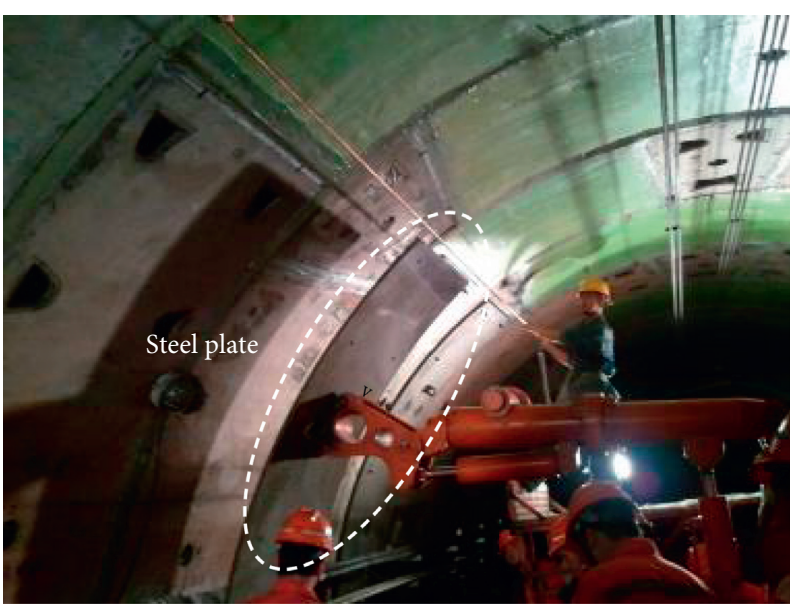

(a)

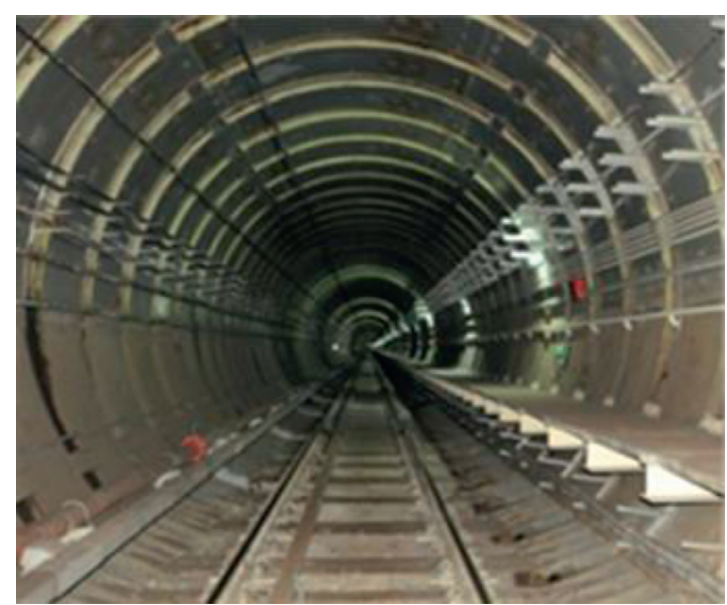

(b)

FIGURE 24: Steel plate strengthening: (a) affixing the steel plate and (b) the overall strengthening effect.

of the tunnel). The grouting points were spaced $2 \mathrm{~m} \times 2 \mathrm{~m}$, and the pressure was controlled under $0.4 \mathrm{MPa}$ to avoid further disturbances on the tunnel structure. Moreover, intensive monitoring of the tunnels was performed, while the correction measures were implemented, and no significant disturbance was detected.

To improve the circumferential stiffness of the tunnel and prevent it from further deformation (horizontal expansion and vertical convergence), the bonded steel plate method [20] was adopted as the interior strengthening method of the tunnels within the alert range $(10 \mathrm{~m}$ to $60 \mathrm{~m})$. The strengthening process is enumerated below. The steel plate was first machined into an arc shape to conform to the intrados of the concrete segmental ring. Corresponding holes were drilled on both the steel plate and segments, and small expansion bolts were adopted to fix the plate onto the segmental inner surface. Finally, the gap between the steel plates and concrete segments was grouted with epoxy resins for adhesion. Figure 24 shows the bonded steel plate strengthening process and overall strengthening effect.

Compared to when the corrective measures began, the eastbound tunnel was measured to be displaced in the negative direction by an average of $2.2 \mathrm{~mm}$ (from the eastbound tunnel to the westbound tunnel). The westbound tunnel was displaced in the negative direction by $1.7 \mathrm{~mm}$. The eastbound and westbound tunnels were measured to be uplifted by $0.2 \mathrm{~mm}$ and $0.4 \mathrm{~mm}$, respectively, on average. These counteracting measures were proven to be effective while mitigating the impacts caused by the adjacent construction.

After finishing the corrective measures, no significant deformation was detected inside either tunnel. The abutment to the distressed tunnel was also recognized as a construction-prohibited area.

\section{Conclusions}

This study presented a case history of the formation mechanism, manifestation characteristics, and corrective measures of tunnel distresses, in which the tunnel settlements, deformations, and observed tunnel distresses were analysed and discussed on the basis of the field measurements, numerical simulations, and theoretical analyses. The lessons learned may provide important references to similar constructions in close proximity to metro tunnels. The following conclusions can be drawn through this study:

(1) For both tunnels, the maximum horizontal displacement was $-9.4 \mathrm{~mm}$, and the settlement was $-14.6 \mathrm{~mm}$ due to the construction of the Hehuang project from January 10, 2004, to August 16, 2008, which is mainly due to foundation pit excavation. The tunnel deformation is mostly concentrated within the alert range $(10 \mathrm{~m}$ to $60 \mathrm{~m}$ away from the station). According to the current deformation monitoring data and the analysis, the deformation of the metro tunnel closely approached its corresponding limitations, but the metro tunnel structure was still in a safe state.

(2) Due to the subsequent construction of the station expansion project, a series of tunnel distresses were observed, including segmental concrete spalling, segmental cracks, interjoint leakage, and an excessive flattening rate. The analyses of the monitoring data revealed that both tunnels sustained horizontal expansion and vertical convergence deformation along the tunnel paths.

(3) For both tunnels, the soil surrounding the tunnels was loosened, and a portion of the connecting bolts yielded within the alert range identified above. When the crack width of a segment reached $0.38 \mathrm{~mm}$, the reinforcement would yield. If the curvature radius of the tunnel decreased to $14,429 \mathrm{~m}$, the bolts would yield, and the longitudinal bending stiffness of the tunnel would decrease rapidly. Therefore, the limitation on the curvature radius of the tunnel was set to $15,000 \mathrm{~m}$.

(4) The causes of the tunnel distresses were discussed, and the lessons learned from the flawed construction 
management were also concluded. Effective countermeasures were directly undertaken on the basis of the analyses, which successfully mitigated and even eliminated some of the detrimental influences on the tunnels caused by the construction. As a result, no further significant deformation was detected inside either tunnel.

\section{Data Availability}

The data used to support the findings of this study are included within the article.

\section{Conflicts of Interest}

The authors declare that there are no conflicts of interest regarding the publication of this paper.

\section{Acknowledgments}

The authors would like to acknowledge the support from the National Natural Science Foundation of China (Grant nos. 51678248 and 51878296), the Independent Research Program of the State Key Laboratory of Subtropical Building Science (Grant no. 2017KB15), the South China University of Technology, and the Open Research Fund of the State Key Laboratory of Simulation and Regulation of Water Cycle in River Basin (Grant no. IWHR-SKL-KF201818).

\section{References}

[1] R. Chen, F. Meng, Z. Li, Y. Ye, and J. Ye, "Investigation of response of metro tunnels due to adjacent large excavation and protective measures in soft soils," Tunnelling and Underground Space Technology, vol. 58, pp. 224-235, 2016.

[2] D. Jin, D. Yuan, X. Li, and H. Zheng, "Analysis of the settlement of an existing tunnel induced by shield tunneling underneath," Tunnelling and Underground Space Technology, vol. 81, pp. 209-220, 2018.

[3] X. Chen, "Research on combined construction technology for cross-subway tunnels in underground spaces," Engineering, vol. 4, no. 1, pp. 103-111, 2018.

[4] M.-G. Li, J.-J. Chen, J.-H. Wang, and Y.-F. Zhu, "Comparative study of construction methods for deep excavations above shield tunnels," Tunnelling and Underground Space Technology, vol. 71, pp. 329-339, 2018.

[5] A. Sharafat, W. A. Tanoli, G. Raptis, and J. W. Seo, "Controlled blasting in underground construction: a case study of a tunnel plug demolition in the Neelum Jhelum hydroelectric project," Tunnelling and Underground Space Technology, vol. 93, p. 103098, 2019.

[6] G. Gao, Y. Zhuang, K. Wang, and L. Chen, "Influence of benoto bored pile construction on nearby existing tunnel: a case study. soils and foundations," Soils and Foundations, vol. 59, 2019.

[7] J. Chai, S. Shen, W. Ding, H. Zhu, and J. Carter, "Numerical investigation of the failure of a building in Shanghai, China," Computers and Geotechnics, vol. 55, pp. 482-493, 2014.

[8] Y. Tan, X. Li, Z. Kang, J. Liu, and Y. Zhu, "Zoned excavation of an oversized pit close to an existing metro line in stiff clay: case study," Journal of Performance of Constructed Facilities, vol. 29, no. 6, 2015.
[9] Z. J. Zhang, M. G. Li, J. J. Chen, J. H. Wang, and F. Y. Zeng, "Innovative construction method for oversized excavations with bipartition walls," Journal of Construction Engineering and Management, vol. 143, no. 8, 2017.

[10] X. G. Li and D. J. Yuan, "Response of a double-decked metro tunnel to shield driving of twin closely under-crossing tunnels," Tunnelling and Underground Space Technology, vol. 28, pp. 18-30, 2012.

[11] H. Huang, H. Shao, D. Zhang, and F. Wang, "Deformational responses of operated shield tunnel to extreme surcharge: a case study," Structure and Infrastructure Engineering, vol. 13, no. 3, pp. 345-360, 2017.

[12] W.-C. Cheng, Z.-P. Song, W. Tian, and Z.-F. Wang, "Shield tunnel uplift and deformation characterisation: a case study from Zhengzhou metro," Tunnelling and Underground Space Technology, vol. 79, pp. 83-95, 2018.

[13] C. Haorong, P. Limin, L. Mingfeng, C. Fudong, and T. Qianlong, "Causes analysis, reinforcement and repair technology of segment crack and damage during shield tunnelling process: a case study," Geotechnical and Geological Engineering, vol. 37, no. 2, pp. 765-773, 2019.

[14] X. Huang, H. F. Schweiger, and H. Huang, "Influence of deep excavations on nearby existing tunnels," International Journal of Geomechanics, vol. 13, no. 2, pp. 170-180, 2013.

[15] J.-J. Chen, L. Zhang, J.-F. Zhang, Y.-F. Zhu, and J.-H. Wang, "Field tests, modification, and application of deep soil mixing method in soft clay," Journal of Geotechnical and Geoenvironmental Engineering, vol. 139, no. 1, pp. 24-34, 2013.

[16] M. G. Li, J. J. Chen, A. J. Xu, X. H. Xia, and J. H. Wang, "Case study of innovative top-down construction method with channel-type excavation," Journal of Construction Engineering and Management, vol. 140, no. 5, 2014.

[17] G. Zheng, T. Zhang, and Y. Diao, "Mechanism and countermeasures of preceding tunnel distortion induced by succeeding EPBS tunnelling in close proximity," Computers and Geotechnics, vol. 66, pp. 53-65, 2015.

[18] Ministry of Housing and Urban-Rural Development of the People's Republic of China, Technical Code for Protection of Structures of Urban Rail Transit, China Architecture \& Building Press, Beijing, China, 2014, in Chinese.

[19] Ministry of Construction of the People's Republic of China, Code for Design of Concrete Structures (GB 50010-2010), China Architecture \& Building Press, Beijing, China, 2010, in Chinese.

[20] T. Liu, H. Huang, R. Xu, and X. Yang, "Research on loadbearing capacity of metro shield tunnel lining strengthened by bonded steel plates," China Journal of Highway and Transport, vol. 30, no. 8, pp. 91-99, 2017, in Chinese. 